\title{
A Cognitive Approach to Moral Responsibility \\ The Case of a Failed Attempt to Kill
}

\author{
PAULO SOUSA * \\ (Forthcoming, Journal of Cognition and Culture, 2009, Vol. 9, 3-4)
}

\begin{abstract}
Many theoretical claims about the folk concept of moral responsibility coming from the current literature are indeterminate because researchers do not clearly specify the folk concept of moral responsibility in question. The article pursues a cognitive approach to folk concepts that pays special attention to this indeterminacy problem. After addressing the problem, the article provides evidence on folk attributions of moral responsibility in the case a failed attempt to kill that goes against a specific claim coming from the current literature - that the dimension of causation is part of the structure of the folk concept of moral responsibility.
\end{abstract}

\section{KEYWORDS}

Folk concepts, moral responsibility, blame, punishment, causality, wrongdoing, moral luck

\section{Introduction}

Cognitive anthropologists are interested in studying the human mind in its universal and culturally specific aspects. Many times, they concentrate their effort on the investigation of the structure of folk concepts. My goal in this article is to advance a

\footnotetext{
* Address correspondence to Paulo Sousa, Institute of Cognition and Culture, Queen's University, Belfast, 2-4 Fitzwilliam Street, BT71NN, Belfast, UK, email: psousa@qub.ac.uk.
} 
cognitive approach to the folk concept of moral responsibility, qua cognitive anthropologist. In particular, I shall discuss how attributions of moral responsibility in the case of a failed attempt to kill speak to a supposed aspect of the structure of this folk concept — the dimension of causation.

The topic of responsibility is already studied in many anthropological traditions - e.g., in legal anthropology (Gluckman, 1972), in linguistic anthropology (Hill and Irvine, 1993), and in the more recently established field of "language and law" that bridges legal and linguistic anthropology (Goldman, 1993). However, for those investigating the structure of folk concepts, there are two limits with the research coming from these traditions. First, because to an important extent the polysemy of words like "responsibility" is not thoroughly explicated and the concept (or concepts) under investigation are not sufficiently delimited, there is some indeterminacy about the import of the claims about responsibility coming from these traditions - in terms both of the description of folk concepts expressed by the word "responsibility" in the context of English and of the cross-cultural translation of folk concepts by the usage of "responsibility" as a tool of the meta-vocabulary of theoretical anthropology. Second, due to the fact that these traditions pursue a different research agenda, they do not provide the type of psychological evidence that would allow testing of detailed hypotheses about conceptual structure.

Those working in cognitive traditions outside anthropology share my goal of studying the structure of the folk concept of moral responsibility and have pursued the relevant type of evidence-e.g., work in developmental psychology (Harris, 1977; Yuill \& Perner, 1988), in social psychology (Shaver 1985, Weiner 1995), and in the burgeoning field of experimental philosophy (Nahmias, Morris, Nadelhoffer \& Turner, 2005; Nichols \& Knobe, 2007). However, to an important extent, these 
traditions talk about moral responsibility or blameworthiness without specifying very clearly the concepts being investigated. Again, there is some indeterminacy about the import of the theoretical claims coming from these traditions.

Given the widespread indeterminacy problem, I shall pursue my goal by clearly demarcating the folk concept of moral responsibility in question. The next two sections delimit this concept in contrast to other concepts important to my discussion-I characterize the intricate polysemy of the word "responsibility," and, subsequently, indicate the concept of my primary research interest and its relation to morality. The following section deals with how attributions of moral responsibility in the case of a failed attempt to kill in the context of American culture speak to a supposed aspect of the structure of this folk concept - the dimension of causation. In the conclusion, I return to the indeterminacy problem in order to clarify the import of my cognitive approach.

\section{The semantic landscape of "responsibility"}

Social scientists, psychologists and philosophers have acknowledged that the word "responsibility" (or "responsible") expresses different concepts both in ordinary language and in more technical discourses (e.g., Baier, 1970; Fliegelman, 1993; Hamilton \& Sanders, 1994; Hart, 1968; Malle et al., 2001; Zimmerman, 1988). In this section, I shall provide a more complete depiction of this polysemy (for a more detailed and formal characterization, see Sousa, in preparation). 
The different meanings of "responsibility" are conveyed by the following story: ${ }^{1}$

Smith is the captain of a ship - he is the one responsible for the ship. As captain, Smith has many responsibilities. In general terms, he is responsible for the safety of the ship and passengers. During his last trip, Smith was very irresponsible - his lack of responsibility was manifest by the fact that many times during the trip he was completely drunk. A heavy storm came, there was an explosion, the ship sank, many passengers died. Being the captain, Smith was held responsible for what happened to the ship and passengers. Legal proceedings were brought against Smith. His lawyer argued first that Smith was insane, but it was attested that he was, and still is, a responsible person - he was and still is responsible for his actions. Then, his lawyer argued that the exceptional storm was responsible for what happened. Finally, he argued that the explosion was a terrorist act, despite the fact that no terrorist organization had claimed responsibility for what happened. The public opinion is that Smith has responsibility for what happened to the ship and passengers. In the end, Smith was found criminally responsible for his reckless behavior.

The first meaning corresponds to the idea of being in command of - the captain is the one in command of the ship. The second corresponds to the idea of obligation - the captain has many obligations; in general, he ought to make sure that the general conditions of the trip remain safe.

Indirect evidence on the dissociation and relation of these two meanings comes from the interpretation of some conventional metaphors commonly used in scientific discourse - "the soma is responsible for the life of the neuron" or "the two hemispheres of the brain have different responsibilities." In asking people to paraphrase sentences like these, some emphasized the first meaning ("the soma is in control of, governs the life of the neuron; the two hemispheres of the brain have different jurisdictions, they are in charge of different things"), whereas others emphasized the second ("the role or job of the soma is to maintain the life of the cell; the two hemispheres have two different duties"). These conventional metaphors

\footnotetext{
${ }^{1}$ I use this concocted story just to frame my exposition ( $c f$. Hart, 1968, p. 211). All additional examples are verbatim transcriptions of natural language use, spoken or written.
} 
highlight the fact that these two meanings are prototypically related to functional roles in a system. The second meaning emphasizes the obligations that each role entails (not only the captain, but also the crew has responsibilities). The first emphasizes that, even if each role is in charge of the some part of the system, some roles have more control over the whole system (the captain has more command than the crew over the ship), involving thereby more autonomy in terms of decisions. These decisions in turn are more important and have more serious consequences for the proper functioning of the system ("I got promoted to another position at my work place: a little more responsibility, a little more money").

The third meaning corresponds to the idea of conscientiousness - the lack of conscientiousness of the captain was manifest by the fact that many times during the trip he was drunk. To be responsible in this sense is to possess the general quality of taking one's obligations seriously. In other words, someone who has this quality “(...) [is] concerned about doing what he ought to do (and not doing what he ought not to do), is generally careful to consider what it is that he ought to do, and careful to see that he does it"(Haydon, 1978, p. 51). Since the captain was not so concerned, he was very irresponsible.

This quality may be considered to be present or absent in a specific situation or, more generally, across situations: One may say that Smith was responsible or irresponsible during a specific voyage or, more generally, that he is a responsible or an irresponsible captain. One may also refer to the decisions, ideas, types of practices, etc. of the persons who have (or lack) this quality—e.g., "it was a responsible (or irresponsible) decision," "this is responsible (or irresponsible) journalism," "this is responsible (or irresponsible) idealism," "he acted responsibly (or irresponsibly)." This concept is sometimes elaborated as part of complex ethical-religious doctrines 
that have as their pedagogic task the development of a sense of responsibility in this sense or as part of sociological theories à la Max Weber that advocate a political attitude based on an ethic of responsibility in a similar sense. Nonetheless, as a commonsense concept, it is underspecified, and, for this reason, in particular contexts, where different normative expectations are at issue, more specific qualities are normally conveyed: One is (or is not) trustworthy and/or thinks about (or does not think about) the consequences of one's actions and/or is (or is not) sensitive to other people's needs or susceptibilities, etc.

The fourth meaning corresponds to the idea of accountability — being the captain, Smith was required to give an account of his actions and omissions to a legitimate authority in relation to what happened to the ship and passengers.

Accountability may be considered a type of second-order obligation normally attached to any type of first-order obligation. Given the first order obligation of the captain (i.e., to make sure that the general conditions of the trip remain safe), when something negative happens in the purview of his first order obligation, he has the obligation to give an account of his actions and omissions to a legitimate authority, if asked to do so. To say that the captain was held responsible means that he was requested to fulfill his second-order obligation and that a process of social evaluation was initiated. The more institutionalized arena of the legal system breaks this process into various stages and opens the possibility of a vicarious account via the defendant's lawyer.

The fifth meaning corresponds to the idea of being in a state of normal adult psychological capacity - his lawyer argued that Smith was not is such a state (i.e., was insane), but it was attested that he had and has the ability to understand his obligations, to make rational decisions according to his obligations, and to follow his 
rational decisions. To be a responsible person in this sense is just to possess such psychological capacities, capacities that may be more or less compromised:

Because 'responsible for his actions' in this sense refers not to a legal status, but to certain complex psychological characteristics of persons, a person's responsibility for his actions may intelligibly be said to be 'diminished' or 'impaired' as well as altogether absent, and persons may be said to be 'suffering from diminished responsibility' much as a wounded man may be said to be suffering from a diminished capacity to control the movements of his limbs. (Hart, 1968, pp. 227-8)

This is one of the meanings of "responsibility" relevant to the legal system, since an enduring and total absence of responsibility in this sense provides a radical excuse, that is, a legitimate insanity defense. It is a commonsense meaning too ("David was seduced by the leader of the sect to believe that Mark was truly evil. He is still responsible for his actions but only somewhat."). ${ }^{2}$ And it is important to note that this meaning does not correspond to the idea of conscientiousness-while lack of capacity-responsibility makes one "nonresponsible," lack of conscientiousnessresponsibility make one "irresponsible":

Sometimes individuals are said to be responsible persons (period), rather than responsible for something. This view attributes to them a measure of moral maturity. Two types of such maturity may be distinguished. In one sense, one

\footnotetext{
${ }^{2}$ Peter Strawson's influential discussion on the compatibility between responsibility and determinism focus on a concept of responsibility that is akin to this one (although those inspired by his approach blend this concept with the last two concepts to be characterized in what follows - cf. Strawson, 1962; Fisher \& Ravizza, 1998; Wallace, 1994). In this context, an incompatibilist who believes in causal determinism would claim that even human beings with the normal adult psychological capacity are not responsible persons_-given causal determinism, one can never be in control of one's actions.
} 
is a responsible person if one has a certain capacity: the capacity to make a reasonable assessment of one's prospective responsibilities (duties, obligations) ... If one is not a responsible person in this sense, one is "nonresponsible." In another sense, one is a responsible person if one takes one's prospective responsibilities seriously and endeavors to fulfill them. If one is not a responsible person in this sense, one is "irresponsible." (Zimmerman, 2001, p. 1487)

The sixth meaning corresponds to the idea of cause - then, his lawyer argued that the exceptional storm was the cause of what happened; or, more specifically, to the idea of intentional cause - the lawyer argued that the explosion was a terrorist act, despite the fact that no terrorist organization had claimed to have intentionally caused what happened.

The seventh meaning corresponds to the idea of blame - the public opinion is that Smith is to blame (or is at fault) for what happened to the ship and passengers, or, in other words, the public opinion places the blame on the captain (the tragedy is his fault). ${ }^{3}$

To clearly indicate the concept at stake here, it is important to emphasize two things. First, the meaning of "blame" here is related to a negative appraisal of a person in relation to a negative event that happened (i.e., the person is at fault for the negative event). It corresponds neither to the simple causal meaning of "blame" ("A freak storm was to blame for the power outage") nor to what may be called the

\footnotetext{
${ }^{3}$ The related sense of "responsibility" is in fact more general (one may call it "appraisability"), since it also includes a similar type of evaluation for positive events, in which someone is given credit for doing something positive or for contributing to something positive that has happened. In my characterization of the concept at stake here, I will be supposing the type of ledger view proposed by Michael J. Zimmerman as the best rendering of the most basic component of this concept (see Zimmerman, 1988).
} 
'reaction' meanings of "blame," which refer to actions such as to censure, to condemn, to reproach, and even to punish. Richard Brandt succinctly points out the distinction between the appraisal and the 'reaction' meanings of "blame":

To be sure, there are performances which we can, without misleading, call "blaming performances." And doubtless "to blame" is often used so as to imply putting on one of these performances. For instance, a person emerging from a "dressing down" might well say, "I certainly got blamed for..." But it would be unfortunate to identify putting on such performances as the exclusive reference of "x blames y for z." (...) For notice how it is natural to say, "He has not said anything to me, and probably nothing to anyone else, but I think he blames me for...." A cool handshake, a reproachful glance, would ordinarily be described rather as symptoms of blaming than as cases of it. And we say, "He blames himself for ..." without necessarily implying any internal preaching. (Brandt, 1958, p. 8) ${ }^{4}$

Second, the type of appraisal involved here is not an evaluation of the character of the person (i.e., it is not an attribution of a dispositional trait such as a defect of character or vice). It is rather an evaluation of the person in relation to $a$ specific negative event - one is to blame (is at fault) for the specific event, not simply tout court (but see Zimmerman, 2002, for a possible qualification). True, the word "fault" may in certain contexts refer to a defect of character, and one may use this

\footnotetext{
${ }^{4}$ The American Heritage Dictionary confounds these two meanings when it says that "blame" stresses censure or punishment and gives an example that can fit only the appraisal meaning: "The police laid the blame for the accident squarely on the driver's shoulders." Some philosophical discussions reduce the meaning of "blame" to the reaction sense - more specifically, to a weaker, non-institutional, form of punishment. Hart's (1968) discussion is prototypical of such an approach. For him, "blameworthy" means simply deserving some form of punishment, and he does not even delineate the appraisal sense of blame as one of the meanings of "responsibility" ( $c f$. Feinberg, 1970; Zimmerman, 1988).
} 
type of trait inference to further infer that a person is to blame for a specific event (or vice-versa), but this does imply that these two concepts are the same.

The eighth meaning of "responsibility" corresponds to the idea of liability — in the end, the captain was deemed susceptible to certain impositions for his reckless behavior. In the context of the criminal law, the typical imposition is to suffer some form of punishment.

This is a meaning of "responsibility" fundamental to the legal system. It is important to note that even if a judgment of liability is normally linked to a judgment of blame - and in the criminal law this correlation is always evoked by the guilty-ornot-guilty verdict - a judgment of blame is not necessary for a judgment of liability, since the legal system allows a judgment of strict liability, which is a judgment of liability irrespective of fault. More importantly, the reason why the concepts of blame and liability are distinct is rather the fact that the component punishment is not an intrinsic to the former, whereas it is intrinsic to the latter: "Legal responsibility is exactly equivalent to liability to punishment. The sole question in every case is: Is this person liable, by the law of the land, to be punished for the act that he has done?" (Taylor, 1898, p. 276). Now, although the legal liability sense of "responsibility" is not a lay meaning of "responsibility," the word "responsible" might also have a related lay meaning, one that could be characterized by the idea of deserving punishment. ${ }^{5}$ However, the concept of blame still differs from this lay liability sense of "responsibility," since again the component punishment is not intrinsic to the former, whereas it is intrinsic to the latter.

\footnotetext{
${ }^{5}$ Paul Fauconnet in his classic treatise La Responsabilité suggests that this is one of the meanings of the ordinary "responsable": "En proposant de les appeler règles de responsabilité, nous nous référons à l'usage commun de la langue ... dans l'usage, les mots responsable et justement punissable sont largement synonymes." (Fauconnet, 1928, p. 07).
} 
Figure 1 represents the concepts expressed by the word "responsibility." Because the words "accountability" and "liability" share part of this polysemy, in the sense that they are also polysemous and refer to a subset of the meanings of "responsibility," the range of their polysemy is indicated as well.

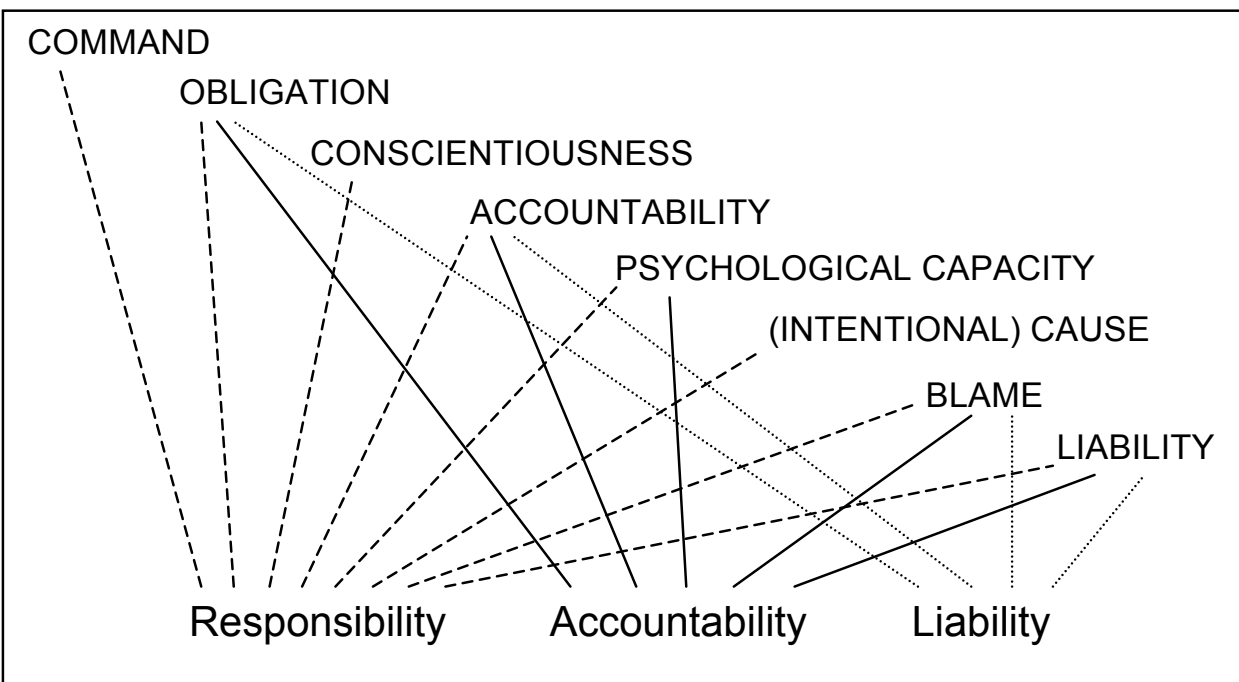

Figure 1 Concepts expressed by "responsibility," "accountability," and "liability"

It is important to note that most of this polysemy is currently present in other languages that have similar words derived etymologically from the Latin, such as French and Portuguese. Furthermore, it is possible that certain words in many other languages evince a somewhat similar polysemy - in particular, one involving the concepts on the right side of Figure 1, as anthropologist Laurence Goldman suggests:

...the term 'responsible' embraces and blends the quite distinct notions of causal denomination, causal agency, fault/blame, and liability ... the ethnographic fact that the English term 'responsible'... frequently conflates a number of distinguishable ideas is indicative of the appreciation of what constitutes liability in the paradigm instance. Here, we may well be in the 
presence of a forensic logic that is near-constant across cultures. The evidence to be had from Melanesian ethnographies is highly suggestive and pertinent in this regard. (Goldman, 1993, p. 42)

\section{Morality comes into the picture}

The folk concept of responsibility that is my primary research interest is the concept blame as characterized. When one is deemed to blame for some event, there is the expectation that one would not bring about the event or let the event happen. My focus is on blame as it relates to contexts where the expectations are framed by the activation of norms, whose transgression entails a sense of wrong-more specifically, by the activation of moral norms, whose transgression entails a sense of moral wrong, as I shall explain.

Not to put too fine a point on it, three of the basic deontic concepts are interdefined as follows: (i) forbidden — what is not permitted to do; (ii) obligatory — what is permitted to do and forbidden not to do; (iii) permitted-what is obligatory to do or what is neither obligatory nor forbidden to do. For the sake of illustration, the action of killing an innocent person is part of what is forbidden, the action of providing adequate care for one's children is part of what is obligatory, and the actions of providing adequate care for one's children (what is obligatory) and going to the cinema (what is neither obligatory nor prohibited) are part of what is permitted. The other two deontic concepts relevant to my discussion relate to the previous ones as follows: (iv) normative-what is obligatory to do or what is forbidden to do; (v) discretionary — what is neither obligatory nor forbidden to do. Here, the actions of providing adequate care for one's children and of killing an innocent person are both 
under the scope of what is normative, and the action of going to the cinema is simply part of what is discretionary. ${ }^{6}$

What is discretionary entails a sense of what is neither right nor wrong; that is, doing or not doing what is discretionary (e.g., going or not going to the cinema) is simply "all right," a question of personal choice. What is normative entails a sense of what is right and a sense of what is wrong; that is, doing what is obligatory is the right thing to do (e.g., providing adequate care for one's children) and doing what is forbidden is the wrong thing to do (e.g., killing an innocent person). Furthermore, because it is obligatory to omit what is forbidden (e.g., to not kill an innocent person) and is forbidden to omit what is obligatory (e.g., to not provide adequate care for one's children), both doing what is obligatory and omitting what is forbidden is right, and both doing what is forbidden and omitting what is obligatory is wrong. Thus, the sense of wrong comes from what transgresses the normative - that is, what does not follow the norms. Figure 2 represents the deontic concepts discussed. ${ }^{7}$

\footnotetext{
${ }^{6}$ It is worth noticing that the word "permitted" is used to refer to what is discretionary as well, which can be considered a case of Grician generalized implicature.

${ }^{7}$ For somewhat different discussions of these basic deontic concepts, see MacNamara, 2006; Mikhail, 2007; Zimmerman, 1986. Cosmides \& Tooby (2008) have raised scepticisms about the psychological plausibility of a domain general deontic logic. However, even if there are only domain specific deontic modules, I presume that some conceptual structure like the one envisaged here is part of the representational repertoire of most of these modules.
} 


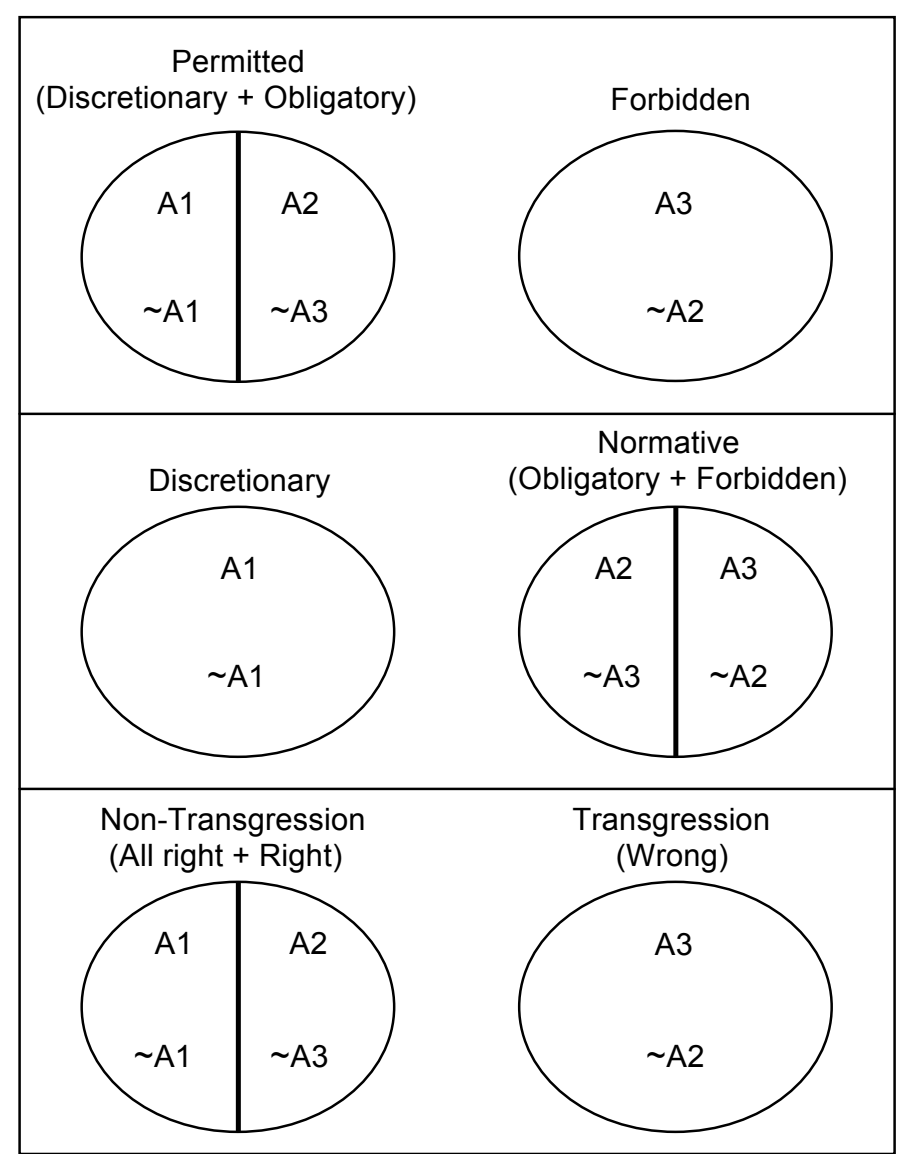

Figure 2 Deontic concepts individuated extensionally $A=$ Action; $\sim A=$ Omission of $A$

Now, what are moral norms, whose transgression entails a sense of moral wrong? There is some consensus in the literature that moral norms are those perceived to be grounded on what is 'intrinsically' normative in contraposition to those norms that are perceived to be simply a product of social consensus. Thus, moral transgressions (e.g., killing an innocent person) entail a sense of what 'intrinsically' wrong, instead of simply something that goes against the social conventions (e.g., 
picking one's nose in public). ${ }^{8}$ It is important to note that this sense of "morality" does not imply any strong opposition between "moral" and "legal." In fact, a distinction that is analogous to the opposition between moral and conventional transgressions has been made for a long time within the common law and remains present in current legal thinking:

Crimes are divided for certain purposes into crimes mala in se (wrong in themselves; inherently evil) and crimes mala prohibita (not inherently evil; wrong only because prohibited by legislation). The distinction, though an ancient one, has survived down to the present time... (LaFave \& Scott, 1986, vol. 1: 45)

In sum, my focus is on blame as it relates to moral contexts as characterized. In what follows, I shall use the word "culpability" to refer to this concept of moral blame. 9

\section{Attempting to kill}

The folk concept of culpability has a graded structure, that is, one may be considered to bear different amounts of culpability:

\footnotetext{
${ }^{8}$ There is also an important dispute in the literature on whether only norms with certain types of content lead to this sense of moral wrong (cf. Haidt et al., 1993; Kelly et al., 2007; Shweder et al., 1987; Sousa, 2009; Sousa et al., forthcoming; Turiel, 1983; Turiel et al., 1987). For my purposes here, I can leave this dispute aside.

${ }^{9}$ Leaving aside the legal level, I'm not supposing any logical implication between wrongdoing (including wrong omissions) and culpability in my characterizations in this section. For a detailed discussion of the logical dissociation between these concepts due to the possibility of excuses or "accuses," see Zimmerman, 1988, 1997, 2004.
} 
(i) He knowingly and intentionally shot her, therefore he deserves all the blame that I placed on him;

(ii) he is almost fully to blame for the death of his aunt. Society deserves a little blame for its focus on material possessions and money that led Sam to kill her;

(iii) David should have realized what was going on and not have fallen for it. However, the leader did brainwash him and so he is only partially to blame;

(iv) there is no doubt that there is a lot of blame to go around here. He should take some of the blame, but he is not the only culpable party.

Consequently, there should be some conceptual variables that constitute the structure of the concept of culpability and whose differential values calibrate the amount of deserved culpability. The study of the structure of this concept is to be related to the characterization of these variables and how they are related to one another. Here, I'm interested in one possible aspect of this graded structure- the relation of causation. Take the examples of a successful assassin and a similar unsuccessful one. The former thinks about killing a person, decides to kill the person, devises a plan, pulls the trigger, and the person dies; the latter thinks about killing a person, decides to kill the person, devises a plan, pulls the trigger, but the bullet does not hit the target, and the person escapes unhurt. Since the relation of causation involves at least a cause and a result (effect), only in the case of the successful assassin is the causal relation between the actions of the assassin (cause) and the death the person (result) instantiated — the absence of a result in the case of the failed attempt implies an absence of causation. Now, does a result affect the extent to which 
one is culpable? Does the successful assassin bear more culpability than the quite similar unsuccessful one?

In moral philosophy, this issue has been discussed under the general heading of moral luck (see Nagel, 1979; Zimmerman, 2002, 2006). In legal philosophy, a similar discussion has been under way for some time (see Kadish, 1994; Moore, 1994). In both contexts, the discussion does not always draw a neat distinction between culpability and liability. Leaving aside these more normative and a priori philosophical discussions, a central tenet in social psychology is that judgments of moral responsibility or blameworthiness presuppose a judgment of causation (see Alicke, 1992; Darley and Shultz, 1990; Shaver, 1985; Weiner, 1995), which would apparently imply a difference between failed attempts and successful attempts in terms of moral responsibility or blameworthiness, since only in the latter is a causal relation instantiated. However, psychologists are not very clear about the concepts of moral responsibility or blameworthiness they have in mind.

The present study is intended to provide some evidence on whether a result makes a difference in the degree of culpability, dealing with the folk-lay conceptual level in the context of American culture. In order to probe the extent to which the concepts culpability and lay liability are correlated in this respect, a question about whether a result makes a difference in the amount of deserved punishment was also included. ${ }^{10}$

\section{Participants}

\footnotetext{
${ }^{10}$ At the folk-legal conceptual level, in most American criminal codes, failed attempts lead to less punishment than would be given if the offense had been completed. In particular, 'attempted murder' leads to less punishment than murder. This is not to say that there is no controversy regarding the point. Actually, the Model Penal Code grades all attempts on equal footing with the completed offense, except in the case of murder. However, in general, real codes have not followed the Model Penal Code proposal in this respect (see Robinson \& Darley, 1995: chapter 2).
} 
The participants were 120 undergraduate students in an introductory psychology class at the University of Michigan who received partial class credit for their participation —all fluently English-speaking Americans (44 females).

\section{Materials and procedure}

In order to prevent participants from interpreting the study as an investigation into what they think is the legal view on the matter, the initial instructions stated clearly and emphatically that the study is interested in participants' own point of view on the matter and that they should use their point of view to answer the questions, regardless of what they think is the legal view (and whether they agree or not with what they think is the legal view). After reading the instructions, each participant was presented with the following two scenarios in this (fixed) order:

SAM was working for a bank, but has lost his job. Now, he desperately wants to have a lot of money. It occurs to him that he will inherit a fortune when his aunt dies. Sam decides to kill his aunt and devises a plan to do so. Sam is lying in wait when he sees his aunt walking out to the car. He raises his rifle and pulls the trigger, and the bullet instantly kills his aunt. Sam is very happy that he killed his aunt, because he will get the fortune soon.

FRED was working for a bank, but has lost his job. Now, he desperately wants to have a lot of money. It occurs to him that he will inherit a fortune when his aunt dies. Fred decides to kill his aunt and devises a plan to do so. Fred is lying in wait when he sees his aunt walking out to the car. He raises his rifle and pulls the trigger, but the bullet misses the target. Fred shoots again, and one more time the bullet misses the target. Hearing the sound of the shots, his aunt manages to escape unhurt. Fred is very upset that he did not kill his aunt, because he won't get the fortune soon.

The scenarios were supposed to describe two situations that were completely equal in terms of the mindset of the main characters, and different only in terms of the success or failure of their attempt to kill (as a reminder, Sam has an "S" of success 
and Fred has an "F" of failure). The introduction of the opposition between being happy about the success versus being upset about the failure was to eliminate any implication of remorse (or regret) in relation to either attempt, and thereby to indicate that neither Sam nor Fred changed his mind at any point during their stories. The use of the second shot was to indicate clearly that, like Sam, Fred fully intended (i.e., without any hesitation) to kill his aunt. This emphasis was necessary because pilot questionnaires had shown that participants tend not to believe that Fred fully intended to kill his aunt given that he failed to do so.

After each scenario, a question probing the extent to which the main character of the scenario was culpable was asked, which was operationalized in three different question-versions: (i) in your opinion, to what extent is Sam [Fred] morally responsible for his aunt's death [for his attempt to kill his aunt]? (ii) in your opinion, to what extent is Sam [Fred] morally at fault for his aunt's death [for his attempt to kill his aunt]? (iii) in your opinion, how much blame does Sam [Fred] deserve for his aunt's death [for his attempt to kill his aunt] $?^{11}$ Participants answered one of these question-versions on an 11-point scale from 0 to 10.

After reading both scenarios and answering their respective questions, participants were presented with two comparison questions in this (fixed) order:

Does it make a difference in terms of culpability whether one tries and succeeds or one tries and fails? In other words, in your opinion, are Sam and Fred culpable to the same extent for what they did in the episodes described by their stories? ${ }^{12}$

Suppose both were caught by the police. Does it make a difference in terms of punishment whether one tries and succeeds or one tries and fails? In other words, in

\footnotetext{
${ }^{11}$ The usage of the word "moral" in some of the questions was simply to avoid having participants interpret the questions in terms of the causal meanings of "responsible" and "at fault" (The combination of "desert" and "blame" in the context of an attempt to kill would do the same job, presumably). I'm not supposing that the ordinary meaning of "moral" necessarily conveys the concept of morality discussed in the previous section.

12 This question was in fact phrased in terms of either "responsibility," "fault," or "blame," following the specific question version of the first probe.
} 
your opinion, do Sam and Fred deserve the same amount of punishment for what they did in the episodes described by their stories?

Participants answered each of the comparison questions by choosing one of the following three ranking options: Sam $=$ Fred; Sam $>$ Fred; Fred $>$ Sam.

A final question, presented after each of the comparison questions, asked participants to provide a justification for their ranking choices. Participants answered this question by writing down a rationale for their specific choices.

\section{Results}

One participant was eliminated from the analysis because, even with the two shots, the participant attributed a different mindset to the character (Fred) of the failed attempt: “On a deep psychological level, Fred didn't want to kill his aunt which is why he missed. So he has less moral responsibility."

The means of participants' culpability ratings are represented in Table 1. Of the comparison options, the one ranking Fred as more than Sam (in terms of culpability or deserved punishment) turned out to be simply a logical possibility—no participant ranked Fred as more than Sam in either comparison. To allow a more relevant and straightforward analysis, I shall ignore this option. The percentages of responses to each of the comparison questions are represented in Table 2, and the percentages of combined responses to the comparison questions are represented in

\section{Table 3.}

Table 1

Means of culpability ratings on a scale from 0 to 10 in each of the question versions $(R=$ responsibility version, $F=$ fault version, $B=$ blame version $)$ 


\begin{tabular}{|c|c|c|c|}
\hline $\mathrm{R}$ & 10.0 & 10.0 & 39 \\
\hline $\mathrm{F}$ & 9.9 & 9.9 & 40 \\
\hline $\mathrm{B}$ & 9.9 & 9.9 & 40 \\
\hline Total & 9.9 & 9.9 & 120 \\
\hline
\end{tabular}

Table 2

Percentages of responses to each of the comparison probes in each of the question versions $(R=$ responsibility version, $F=$ fault version, $B=$ blame version)

\begin{tabular}{|c|c|c|c|c|}
\hline \multirow{2}{*}{} & \multicolumn{2}{|c|}{$\begin{array}{r}\text { CULPABILITY } \\
\text { COMPARISON }\end{array}$} & \multicolumn{2}{c|}{$\begin{array}{r}\text { PUNISHMENT } \\
\text { COMPARISON }\end{array}$} \\
\cline { 2 - 5 } & Sam = Fred & Sam > Fred & Sam = Fred & Sam > Fred \\
\hline $\mathrm{R}$ & $90.0 \%$ & $10.0 \%$ & $54.0 \%$ & $46.0 \%$ \\
\hline $\mathrm{F}$ & $95.0 \%$ & $5.0 \%$ & $60.0 \%$ & $40.0 \%$ \\
\hline $\mathrm{B}$ & $82.5 \%$ & $17.5 \%$ & $60.0 \%$ & $40.0 \%$ \\
\hline Total & $89.0 \%$ & $11.0 \%$ & $58.0 \%$ & $42.0 \%$ \\
\hline
\end{tabular}

Table 3

Percentages of combined responses to the comparison probes in each of the question versions ( $R=$ responsibility version, $F=$ fault version, $B=$ blame version)

\begin{tabular}{|c|c|c|c|c|}
\hline \multirow{2}{*}{} & \multicolumn{4}{|c|}{$\begin{array}{r}\text { CULPABILITY COMPARISON } \\
\text { PUNISHMNT COMPARISON }\end{array}$} \\
\cline { 2 - 5 } & $\begin{array}{c}\text { Sam }=\text { Fred } \\
\text { Sam }=\text { Fred }\end{array}$ & $\begin{array}{c}\text { Sam }=\text { Fred } \\
\text { Sam }>\text { Fred }\end{array}$ & $\begin{array}{c}\text { Sam }>\text { Fred } \\
\text { Sam }>\text { Fred }\end{array}$ & $\begin{array}{c}\text { Sam }>\text { Fred } \\
\text { Sam }=\text { Fred }\end{array}$ \\
\hline R & $51.5 \%$ & $38.5 \%$ & $7.5 \%$ & $2.5 \%$ \\
\hline F & $57.5 \%$ & $37.5 \%$ & $2.5 \%$ & $2.5 \%$ \\
\hline B & $55.0 \%$ & $27.5 \%$ & $12.5 \%$ & $5.0 \%$ \\
\hline Total & $54.5 \%$ & $34.5 \%$ & $7.5 \%$ & $3.5 \%$ \\
\hline
\end{tabular}

In relation to Table 1, a 2 (scenario type) x 3 (question version) mixed ANOVA showed no main effects or interaction. In relation to Table 2, chi-square tests for independence showed no significant difference between the results of the different question versions - in the culpability comparison, $\chi^{2}(2, N=119)=3.23, p=.19, n s$; in the punishment comparison, $\chi^{2}(2, N=119)=.40, p=.81, n s$. And chi-square tests for goodness-of-fit on the totals showed a significant and a marginally significant 
difference - in the culpability comparison, $\chi^{2}(1, N=119)=72.68, p<.001$; in the punishment comparison, $\chi^{2}(1, N=119)=3.03, p=.08$. In relation to Table 3 , a chisquare test for independence showed no significant difference between the results of the different question versions $-\chi^{2}(6, N=119)=4.12, p=.66, n s$. And a chi-square test for goodness-of-fit on the totals showed a significant difference- $-\chi^{2}(3, N=119)$ $=82.78, p<.001$.

Not only were participants' mean ratings the same in each of the scenario conditions (9.9), but also the great majority of participants directly ranked Sam and Fred as bearing culpability to the same degree (89\%). Participants' justifications for regarding them equally culpable invariably appealed to the identity of their mental processes and attempts: ${ }^{13}$

$[\mathrm{C} / \mathrm{R}$; Sam $=$ Fred $]$ Both made conscious decisions to murder their aunts. Morally speaking, the fault is the same. That is, the moral fault was committed before any shots were even fired.

$[\mathrm{C} / \mathrm{R}$; Sam $=$ Fred $]$ Because there was absolutely no difference in the thought process between the two. It just happens that one is a horrible shot.

$[\mathrm{C} / \mathrm{F}$; Sam $=$ Fred $]$ Regardless of their success, both are fully responsible (at fault) for their actions. Success is not a relevant factor in assessing the degree of fault.

$[\mathrm{C} / \mathrm{F}$; Sam $=$ Fred $]$ They both had the same intentions to kill for the same reasons. Just because Fred has bad aim does not make him less at fault morally.

$[\mathrm{C} / \mathrm{B} ; \mathrm{Sam}=$ Fred]: Both had the same motive, intent to kill and plan to do so. Sam may have hit his mark out of skill or luck, but that doesn't matter. Both are equally guilty.

\footnotetext{
13 In what follows, the bracketed information related to participants' justifications indicates the comparison probe $(\mathrm{C}=$ culpability; $\mathrm{P}=$ punishment $)$, the question version $(\mathrm{R}=$ responsibility; $\mathrm{F}=$ fault; $\mathrm{B}=$ blame $)$ and the option being justified $(\mathrm{Sam}=$ Fred; Sam $>$ Fred $)$.
} 
$[\mathrm{C} / \mathrm{B}$; Sam $=$ Fred $]$ The question here is blame, not outcome. Both experienced the same mental processes and took the same actions - so they have equal blame.

The majority of participants considered Sam and Fred to be equal both in culpability and deserved punishment (54.5\%). Most of these participants appealed to the same criterion of identity of mindset and attempt in both justifications:

$[\mathrm{C} / \mathrm{R}$; Sam $=$ Fred $]$ They both had full intentions of killing their aunt. Just because Fred was a bad shot doesn't mean that he isn't as morally responsible as Sam.

[P; Sam = Fred $]$ They both had full intentions to kill, so they should receive the same punishment.

$[\mathrm{C} / \mathrm{R}$; Sam $=$ Fred $] \mathrm{I}$ believe intentions matter most because if Fred had his way his aunt would be dead and Sam and Fred would clearly be equal. The fact that he's a bad shot shouldn't reward him.

[P; Sam = Fred] I think the law would choose the second option but I think it's the intention that matters most.

$[\mathrm{C} / \mathrm{F}$; Sam $=$ Fred $]$ Morality is a mental concept, one of intentions. If one tries to save someone from falling down a cliff, but their hand slips that person is not morally responsible for the death.

$[\mathrm{P} ; \mathrm{Sam}=$ Fred $]$ Murder and attempted murder are the same in my mind. Both men are murderers; one is simply a less effective murderer.

$[\mathrm{C} / \mathrm{F}$; Sam $=$ Fred $]$ They had the same intentions in attempting to kill their aunts. There is no moral difference that one hit the target and the other didn't. $[\mathrm{P} ; \mathrm{Sam}=$ Fred $]$ They deserve the same punishment because their intentions were the same and their attempts were the same, their outcomes were just different.

$[\mathrm{C} / \mathrm{B}$; Sam $=$ Fred $]$ Their stories are pretty much the same with the exception that Fred's attempt to kill his aunt isn't successful. They were both aiming for the same goal and both had the same mindset.

[P; Sam $=$ Fred $]$ Their thought processes were the same, regardless of whether or not Fred succeeded. Fred intended on killing his aunt, which in my mind is just as bad as actually killing her.

$[\mathrm{C} / \mathrm{B} ; \mathrm{Sam}=$ Fred $]$ Both Sam and Fred set out with the same intentions.

$[\mathrm{P} ; \mathrm{Sam}=$ Fred $]$ Even though only one murder was carried out both men had the same intent and deserve the same punishment. 
Many participants considered the two characters to bear culpability to the same degree but thought that Sam deserves more punishment (34.5\%). These participants' justifications emphasized that the resulting death made a difference in terms of deserved punishment:

$[\mathrm{C} / \mathrm{R}$; Sam $=$ Fred $]$ They're the same because the intentions were the same. Had Fred not missed, the outcomes of the situations would be the same. [P; Sam > Fred] While they are equally responsible, the fact is that Sam took a life. That extra step makes a big difference, especially to those around the victim.

$[\mathrm{C} / \mathrm{F}$; Sam $=$ Fred $]$ They have the same thought process and decision making. The only difference is that Sam was a better shot and that doesn't change morality.

[P; Sam > Fred] Even though the motive is the same, no one was killed in Fred's case so he deserves less.

$[\mathrm{C} / \mathrm{B}$; Sam $=$ Fred $]$ They both had the same intention, so no matter what the result was, each is in full blame.

[P; Sam > Fred] They both had the same intention but the result of Sam's action was more severe since the aunt did die.

A small number of participants ranked Sam more than Fred in terms of both culpability and deserved punishment (7.5\%) and suggested that the resulting death made a difference in both comparisons: ${ }^{14}$

$[\mathrm{C} / \mathrm{R}$; Sam $>$ Fred] But not by a great deal... but results do have some effect on responsibility. [P; Sam > Fred] But not by a lot.

[C/F; Sam $>$ Fred] Sam actually stole a life. The universe gave Fred another chance. Both are in the wrong but Sam's "moral fault" is more extreme. [P; Sam > Fred] It is not fair to punish both for taking a life when only one did.

[C/B; Sam > Fred] I feel Fred should get full blame for the attempt, but he did not actually kill, so there is where the difference lies in my opinion.

\footnotetext{
${ }^{14}$ The justifications of the participants (3.5\%) who considered Sam to bear more culpability and to deserve equal punishment suggest that they either reversed the interpretation of the comparison questions or were confused.
} 
[P; Sam > Fred] In one instance somebody is dead, in another they are not, so punishment should be different.

Thus, almost half of participants (42\%) thought that Sam deserves more punishment, highlighting the relevance of a result to judgments of liability.

\section{Discussion}

Notice that, in the initial ratings, participants judged Sam and Fred to bear full culpability for two different things: for the death (a result) and for an attempt (without a result). Therefore, from these ratings themselves, one could not conclude that the death does not add anything to a simple attempt—judging Sam fully culpable for the death and Fred fully culpable for the failed attempt does not necessarily imply judging both equally culpable. Nonetheless, given that the great majority of participants directly ranked Sam and Fred as having equal culpability, one can indeed conclude that for these participants the death does not add anything in degree of culpability.

A central tenet in social psychology is that judgments of moral responsibility presuppose the attribution of a causal relation: “... judgments of moral responsibility presuppose those of causation. If the protagonist is judged not to have caused the harm, then there is no need to consider whether he is morally responsible for it" (Darley and Shultz, 1990, p. 531). If "moral responsibility" is interpreted in terms of culpability, my evidence goes against this general tenet, since the absence of a bad result in the case of the failed attempt (hence, the absence of causation) did not affect most participants' judgments of culpability. But the tenet may concern only contexts where a bad event occurred, in which case the less the causal contribution of the person to the occurrence of the event, the less the person bears culpability (no causal 
contribution, no culpability), and the more the causal contribution of the person to the occurrence of the event, the more the person bears some but not necessarily all culpability (total causal contribution does not entail full culpability because causality is to be considered only one dimension of culpability, among others such as level of intentionality). My evidence also denies that causation is a dimension of culpability in this sense, since the great majority of participants did not see any difference between the failed and the successful attempt, showing that for them the fact of causing the death in the case of the successful attempt does not add anything in degree of culpability. $^{15}$

What my evidence suggests is that, for most participants, the fundamental factor in attributing full culpability was the decision of the agents. Even the attempts themselves may not add anything other than evidence confirming that the agents had really decided to kill their innocent aunts — the attempts may just confirm that they really had a full intention to kill, that they were really decided to kill.

If "moral responsibility" is interpreted in terms of liability, my evidence gives a qualified support to the tenet, since a good amount of participants considered Sam to deserve more punishment than Fred. ${ }^{16}$ But why for many participants is causation more relevant in this respect? Although this is not the main topic of this article, and my evidence does not clearly suggest an answer, let me briefly put forward the following speculative hypothesis: it may be that the result was perceived to increase the badness of the wrongdoing, an increase that in turn affected judgments of liability more than judgments of culpability. In other words, participants may have judged not

\footnotetext{
${ }^{15}$ Some results related to contexts of causal deviance also support the claim that causation is not a dimension of culpability (Sousa \& Holbrook, forthcoming).

${ }^{16}$ Cushman (2008) provides evidence that goes in the same direction, though he obtained similar results in judgments of blame, which, in my opinion, suggests that his participants interpreted the blame question either in term of causality or in terms of punishment, but not in terms of culpability.
} 
only that the Sam did more wrongs than Fred (i.e., Sam attempted to kill and killed his aunt) but also that he did something worse, which deserves more punishment.

\section{Conclusion}

As I mentioned in the introduction, there is a kind of indeterminacy problem in the current literature. Most of the time, researchers do not clearly specify the folk concept(s) of responsibility under inspection. This problem becomes even trickier when the explicit aim is to study folk concepts or the judgments deploying them.

Some researchers in psychology have discussed this indeterminacy problem (e.g., Fincham \& Jaspars, 1980; Robbennolt, 2000). In what is the best review of the literature in social psychology related to the topic of responsibility up until the end of the seventies, Fincham and Jaspars say:

... the unacknowledged vacillation between different uses of the term

"responsibility" and its lack of differentiation from related concepts (e.g., punishment) generates a lack of conceptual clarity for the reader... this call for a more adequate conceptual analysis of the notion in the psychological literature ... (1980, p. 85)

That responsibility should not be equated with causality becomes apparent from the preceding analysis. The confusion in psychological writings arises partly because causality constitutes one meaning of the word "responsibility." ... The central meaning of responsibility, however, is different from that of causality. Holding someone responsible by demanding that he rebut an 
accusation does not explain his actions but simply indicates liability for punishment (blame ${ }^{17}$ ), or compensation. The confusing results obtained in accident research may be partly caused by certain studies having used responsibility in a causal sense, whereas others have used it to mean moral blame or evaluation.(1980, p. 104)

However, note that the lack of detailed specification afflicts even those like Fincham and Jaspars who are concerned about the problem. Thus, throughout their otherwise careful review of the literature, they do not clearly distinguish the concepts of accountability and liability, and no clear discussion of the concept of culpability emerges in their article.

To give another example in psychology, consider Kelly Shaver's book The Attribution of Blame: causality, responsibility and blameworthiness (1985), where one of the most comprehensive and detailed information-processing models related to the topic of responsibility and blame is put forward, dividing the process of blame assignment into the sequential stages of causal attribution, responsibility attribution, and finally blame. However, when one reads the book carefully, it becomes patent that Shaver oscillates between different meanings of the words "responsibility" and "blame" throughout the book, and that he is rather confused in his claims about responsibility and blame. ${ }^{18}$ Take these passages:

\footnotetext{
${ }^{17}$ In the original, this passage is written "punishment (praise)," but Fincham (personal communication) says that this was a typo and should be read "punishment (blame)."

${ }^{18}$ For similar examples of an unclear attempt to distinguish responsibility from blame, see Alicke, 2000; Shultz \& Scheiler, 1983; Weiner, 1995.
} 
The related, but conceptually distinct, issues of causality, responsibility, and blameworthiness that are the subject of this book play a critical role in our everyday social encounters. (1985, Preface; my emphasis)

At first it might appear that the straightforward questions about causality, responsibility, and culpability would have an equally direct answer... (1985, p. 1 ; my emphasis)

What retributivism does suggest is that the degree of moral culpability and subsequent blame or punishment should be dictated by the gravity of the original offense.(1985, p. 155; my emphasis)

In some parts of the book, Shaver seems to equate blame with culpability, as the first two passages above suggest, but in other parts he seems to equate blame with something akin to an informal form of punishment, as the third passage above suggests. His discussion of responsibility is equally equivocal. He seems to use "responsibility" sometimes to mean simply intentional agency, sometimes to mean accountability or liability. We end up with a detailed model of the variables relevant to judgments of responsibility and blame; nonetheless, it is unclear which concepts of responsibility and blame are supposed to be deployed in these judgments.

Finally, take recent work in experimental philosophy dealing with the question of whether the folk concept of moral responsibility is incompatible with causal determinism - i.e., whether the assumption of causal determinism would entail the impossibility of being morally responsible to any extent. In one the target articles of a special issue that I edited for this journal (see Sousa, 2006), Shaun Nichols reports 
evidence that according to him indicates, with some qualifications, that the folk are incompatibilists (see Nichols, 2006; Nichols \& Knobe, 2007). In the beginning of the article, he says:

The relevant notion of moral responsibility itself is contentious in the free will debates. For the purposes of this paper, I intend "moral responsibility" to pick out the notion of responsibility that is tied to moral desert, blame, and retributive punishment. (2006, p. 58, n. 1)

And later in the same issue, in response to counter evidence raised in one of the commentaries to his article, Shaun Nichols says:

One key difference between the studies is that Nahmias asks subjects whether agents in the universe "deserve credit or blame for their actions" whereas we ask whether agents can be "fully morally responsible." We chose our wording because incompatibilists (e.g. Galen Strawson) tend to acknowledge that there are notions of responsibility that are consistent with determinism. What incompabilists maintain is that the kind of strong moral responsibility that most people endorse is not compatible with determinism. Hence, to be as accommodating as possible to the incompatibilist, we used an expression that was deliberately strong. So one explanation for Nahmias' results in the psychological determinist scenario is that people are willing to grant that agents in a psychologically determinist universe deserve some blame and credit; but those same people might still maintain that the agents in that 
universe don't deserve the kind of full blame that is reserved for those presumed to have libertarian free will. (2006, p. 313)

It is quite difficult to know which folk concept of moral responsibility Nichols has in mind - the initial remark does not do much more than acknowledge the indeterminacy problem; the later remark does not delimit a specific concept either, since a full amount of blame does not in itself characterize a different concept of blame. Furthermore, given the way the question about moral responsibility was framed, it is difficult to accept that Nichols' (and Knobe's) research provides evidence for the claim that the folk are incompatibilist — the fact that many participants denied full moral responsibility in causal determinist scenarios does not preclude the possibility that these participants would attribute a great deal of moral responsibility in the same scenarios.

In this article, I have pursued a different strategy. I started by seriously addressing the indeterminacy problem; then I described my research accordingly. I'm aware that my specific interpretations, methodological choices and results are not without problems, but I'm fairly confident that this overall strategy is a reasonable way to advance a cognitive approach to the topic of moral responsibility.

\section{References}

Alicke, M. (2000). Culpable control and the psychology of blame. Psychological Bulletin, 126, 556-574.

Baier, K. (1970). Responsibility and action. In M. Brand (ed.) The nature of human action. Scott, Foresman and Company. 
Brandt, R. (1958). Blameworthiness and obligation. In A. I. Melden (ed.) Essays in Moral Philosophy. Seatle: University of Washington Press.

Cosmides, L. \& Tooby, J. (2008) Can a general deontic logic capture the facts of human moral reasoning? In Walter Sinnott-Armstrong (ed.) Moral Psychology (vol. 1, the evolution of morality: adaptations and innateness), The MIT Press, pp. 53-164.

Cushman, F. (2008). Crime and punishment: distinguishing the roles of causal and intentional analyses in moral judgment. Cognition, 108(2), 353-380.

Feinberg, J. (1970). Doing and Deserving. Princeton: Princeton University Press.

Fincham, F. \& Jaspars, J. (1979). Attribution of responsibility to the self and other in children and adults. Journal of Personality and Social Psychology, 37, 15891602.

Fisher, J. \& Ravizza, M. (1998). Responsibility and Control. Cambridge: Cambridge University Press.

Fliegelman, J. (1993). Declaring Independence. Stanford: Stanford University Press.

Fauconnet, P. (1928). La Responsabilité. Paris: Félix Alcan.

Gluckman, M. (ed.) (1972). The allocation of responsibility. Manchester: Manchester University Press.

Goldman, L. (1993). The culture of coincidence: accident and absolute liability in Huli. New York: Clarendon Press.

Haidt, J., Koler, S., and Dias, M. (1993). Affect, culture and morality, or is it wrong to eat your dog? Journal of Personality and Social Psychology, 65, 613 -628.

Hamilton, L. \& Sanders, J. (1992). Everyday Justice. New Haven: Yale University Press.

Harris, B. (1977). Developmental differences in the attribution of responsibility. 
Developmental Psychology, 13(3), 257-265.

Hart, H. L. A. (1968). Punishment and Responsibility. Oxford: Oxford University Press.

Haydon, G. (1978). On being responsible. The Philosophical Quarterly, 28, 46-57.

Hill, J. \& J. Irvine. (1993). Responsibility and Evidence in Oral Discourse.

Cambridge: Cambridge University Press.

Kadish, S. H. (1994). The criminal law and the luck of the draw. Journal of Criminal Law and Criminology, 98, 679-690.

Kelly, D., Stich, S., Haley, K., Eng, S. and Fessler, D. (2007). Harm, affect, and the moral/conventional distinction. Mind and Language, 22, 117-131.

LaFave, W.R. \& Scott, A.W. 1986. Substantive Criminal Law (Vol. 1). St. Paul, MINN: West Publishing Co.

Malle, B., Moses, J. \& D. Baldwin (Eds.) (2001). Intentions and Intentionality. MA: MIT Press.

MacNamara, P. (2006). Deontic logic. In Edward N. Zalta (ed.), The Stanford Encyclopedia of Philosophy. Retrieved March 7, 2007, from http://plato.stanford.edu/entries/logic-deontic/

Mikhail, J. (2007). Universal moral grammar: theory, evidence and the future. Trends in Cognitive Sciences, 11, 143-152.

Moore, M. S. (1994). The independent moral significance of wrongdoing. Journal of contemporary legal issues, 1, 271-278.

Nagel, T. 1979. Mortal Questions. Cambridge: Cambridge University Press.

Nahmias, E., Morris, S., Nadelhoffer, T. \& Turner, J. (2005). Surveying Freedom: Folk Intuitions about Free Will and Moral Responsibility. Philosophical Psychology, 18, 561-584. 
Nichols, S. \& Knobe, J. (2007). Moral Responsibility and Determinism: The Cognitive Science of Folk Concepts. Nous, 41, 663-685.

Pizarro, D., Ulhman, E. and Bloom, P. (2003). Causal deviance and the attribution of moral responsibility. Journal of Experimental Social Psychology, 1-8.

Robbennolt, J. (2002). Outcome Severity and Judgments of "Responsibility": A MetaAnalytic Review. Journal of Applied Social Psychology, 30, 12, 2575-2609.

Robinson, P. \& Darley, J. 1995. Justice, Liability, and Blame: Community Views and the Criminal Law.

Shaver, K.G. (1985). The Attribution of Blame: causality, responsibility and blameworthiness. New York: Springer.

Shultz, T. R, and Schleifer, M. (1983). Towards a refinement of attribution concepts. In J. Jaspars, F. D. Fincham, \& M. Hewstone (Eds.), Attribution Theory and Research, pp. 37-62. London: Academic Press.

Shweder, R. A., Mahapatra, M. \& Miller, J. (1990). Culture and moral development. In J. Stigler, R. Shweder, and G. Herdt (eds.) Cultural Psychology-essays on comparative human development. Cambrige: Cambridge University Press. (pp. 130-204).

Sousa, P. (2009). On testing the 'moral law'. Mind \& Language, 24, 209-234.

Sousa, P. (in preparation). The folk concept of moral responsibility.

Sousa, P. \& Holbrook, C. (forthcoming). Folk concepts of intentional action (in the contexts of amoral and immoral luck). European Review of Philosophy.

Sousa, P., Holbrook, C. \& Piazza, J. (forthcoming). The morality of harm. Cognition. Strawson, P. (1962). Freedom and Resentment. Proceedings of the British Academy, $48,187-211$.

Taylor, T. (1989). The Law and Responsibility. The Philosophical Review, 7, 3: 276- 
285.

Turiel, E. (1983). The development of social knowledge - morality and convention. Cambridge: Cambridge University Press. (pp. 33-74)

Turiel, E., Killen, M. \& Helwig, C. (1987). "Morality: Its structure, Functions, and Vagaries", dans J. Kagan and S. Lamb (eds.) The Emergence of moral concepts in young children, Chicago: University of Chicago Press, 155-244.

Wallace, R. J. (1994). Responsibility and the Moral Sentiments. Cambridge: Harvard University Press.

Weiner, B. (1995). Judgments of responsibility. New York: Guilford Press.

Zimmerman, M. (1988). An essay on Moral Responsibility. New Jersey: Rowman \& Littlefield.

Zimmerman, M. (1997). A plea for accuses. American Philosophical Quarterly, 34, 229-243.

Zimmerman, M. (1986). The Concept of Moral Obligation. Cambridge: Cambridge University Press.

Zimmerman, M. (2001). Responsibility. In L. Becker (ed.), Encyclopedia of Ethics. New York: Garland Publishing.

Zimmerman, M. (2002). Taking luck seriously. Journal of Philosophy, 99, 553-576.

Zimmerman, M. (2004). Another plea for excuses. American Philosophical Quarterly, $41,259-266$.

Zimmerman, M. (2006). Moral luck: a partial map. Canadian Journal of Philosophy, $36,585-608$

Yuill, N., \& Perner, J. (1988). Intentionality and knowledge in childrens' judgments of actors responsibility and recipients emotional reaction. Developmental Psychology, 24(3), 358-365 
